\title{
Liberal fortification of foods: the risks. A study relating to Finland
}

\author{
A Suojanen, S Raulio, M-L Ovaskainen
}

J Epidemiol Community Health 2002;56:259-264

\begin{abstract}
Study objective: The free circulation of goods in the European Union (EU) has increased the number of fortified foods available to consumers in Finland. Fortification of foodstuffs with calcium is currently widespread. To assist decision making relating to fortification, the object of this study was to determine whether there might be a risk of excessive levels of calcium. The study was done using the dietary data of adult population by sex and calcium intake deciles, taking account of intakes of calcium from normal diets and from fortified foods.

Study design: Calcium intakes for deciles were calculated from dietary data of the population involved in the 1992 FINDIET survey. Calcium fortification was evaluated by considering foodstuffs to which calcium has already been added or which producers might wish to fortify and market in Finland. Situations in which a fortified product replaced its unfortified equivalent were envisaged. Daily calcium intakes $(\mathrm{mg})$ from particular foodstuffs were calculated based on known amounts of calcium $(\mathrm{mg})$ per $100 \mathrm{~g}$ of each foodstuff and amounts of each product consumed per day. Total calcium intakes of people in different deciles were calculated by adding amounts of calcium contributed by each fortified product to normal dietary intakes. Calcium intakes were also calculated for consumption by persons of all foodstuffs that are or intended to be fortified with calcium.

Study participants: Adults aged 25 to 64 representing populations in four regions of Finland, who recorded food consumption over three day periods in spring 1992.

Study setting: North Karelia, Kuopio Province, Turku-Loimaa, and the capital area Helsinki-Vantaa, Finland.

Main study results: The results indicate that the highest 10\% of Finnish adult men receive on average $2315 \mathrm{mg}$ calcium per day from diets that do not include fortified foodstuffs. These people whose energy consumption was high consumed substantial amounts of dairy products. Consumption of fortified foods would increase the calcium intake further to levels exceeding the tolerable upper intake level $(2500 \mathrm{mg} / \mathrm{d})$.

Conclusions: Liberal addition of calcium to various groups of foodstuffs could increase the calcium intake in the highest decile to levels with potentially untoward health effects. In assessing benefits and possible disadvantages of fortification of foodstuffs, the dietary habits of the population concerned, probable consumption of fortified products and nutritional intakes, especially at extremes, need to be taken into account, by total risk assessment.
\end{abstract}

See end of article for authors' affiliations

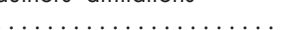

Correspondence to: Susanna Raulio, PO Box 28, FIN-00581 Helsinki, Finland;

susanna.raulio@nfa.fi

Accepted for publication 12 September 2001 a n Finland, fortification (in this article fortification means adding vitamins or minerals to foodstuffs for nutritional purposes) of foodstuffs began in the 1940s. Vitamins A and D were added to margarine, used as a substitute for butter, because night blindness and rickets had been seen in the population. Endemic goitre was also prevented by the addition of iodine to table salt. In the 1970s and 1980s, iron and thiamine were added to white flour to compensate for low intakes, and vitamin $\mathrm{C}$ was added to fruit juice, mainly to restore vitamins destroyed in processing. All fortification measures had been considered by the food and health authorities. The object of adding vitamins and minerals to foodstuffs was to improve public health in Finland, or at least to benefit particular groups of consumers, on the basis of results of dietary studies that showed lack or insufficient intake of a particular nutrient.

Finland joined the European Union (EU) in the year 1995. There is free circulation of foodstuffs within the Union. In many EU countries fortification of foodstuffs is liberal. ${ }^{1}$ Accordingly, increased amounts of fortified foodstuffs have come to the Finnish market. Fortification now affects not only fruit juice (in this article fruit juice means juice with added water or sugars and with a juice content of at least 35\% by weight) and sweets but also, for example, dairy and cereal products, and edible fats. As fortification has increased in extent the authorities have not only had to estimate its benefits but also determine whether there might be adverse effects from the added nutrients in different population groups. The issue is actual because European Commission has planned to give the first draft for harmonised EU legislation on food fortification in the near future. In that context scientists and policy makers will discuss for example how the cumulative intake of nutrients should be taken into account and how the responsibilities will be shared by governments, food industry, and consumers.

In this study calcium intakes were compared with Nordic and Finnish limit values ${ }^{23}$ : minimum requirement 400 $\mathrm{mg} /$ day, recommended adequate intake $800 \mathrm{mg}$ /day, tolerable upper intake level $2500 \mathrm{mg} /$ day. The Scientific Committee for Food has also stated the minimum threshold intake of calcium to be $400 \mathrm{mg} /$ day. ${ }^{4} \mathrm{EU}$ and the United States of America have the same tolerable upper intake level of calcium as the Nordic Countries $\left(2500 \mathrm{mg} /\right.$ day). ${ }^{45}$ In this study calcium intakes from the diets of Finnish adults were examined, and the effects of fortification with calcium on total intake, especially at the upper extreme, were calculated.

Calcium was chosen for the study because in Europe, Finns have the highest consumption of milk and milk products (374 $\mathrm{kg} /$ year/person in Finland versus $239 \mathrm{~kg}$ in Germany or $233 \mathrm{~kg}$ in UK). ${ }^{6}$ It is also known that the diets of some population 
Table 1 Calcium levels in fortified foods

\begin{tabular}{ll}
\hline Foods & $\begin{array}{l}\text { Calcium content after } \\
\text { fortification } \mathrm{mg} / 100 \mathrm{~g}\end{array}$ \\
\hline Fruit juice and fruit drinks & $120^{*}$ \\
Low fat and fat free milk & $180 \dagger$ \\
Hot and cold breakfast cereals & $80 \ddagger / 450 \ddagger$ \\
Wheat and mixed grain bread & $472 \ddagger$
\end{tabular}

*Calcium content is based on general permission by KTM

$(113 / 1998)$ and on individual authorisations; †calcium content is based on individual authorisation, calcium content of natural milk is $120 \mathrm{mg} / 100 \mathrm{~g}$; łcalcium content is based on recent applications.

groups contain abundant calcium. The other reason for selecting calcium for study was that it is a nutrient, which the food industry at the moment particularly wishes to add to different foodstuffs. The worldwide increase in osteoporosis, ${ }^{7}$ including Finland $^{8}$ is stated to be the reason for increasing interest to add calcium. The purpose of this study was to determine whether those population groups, which get a lot of calcium from their diet, were likely to be at risk of excessive intake of calcium if liberal fortification of foods with calcium would be practised. Risk assessment was needed to support especially those food authorities that were making decisions on fortification.

\section{METHODS \\ Study population}

The data for the study were obtained from the 1992 FINDIET survey, carried out in connection with the 1992 FINMONICA survey. The sample was representative of the population aged 25 to 64 in four areas (North Karelia, Kuopio Province, TurkuLoimaa, and the capital area Helsinki-Vantaa) of Finland. A subsample $(n=2822)$ was selected for the dietary survey. ${ }^{9} 10$ Altogether 2148 of those invited attended health study centres. Each subject was instructed how to keep a three day food record. Food records were returned by mail from 1949 subjects and for 1861 subjects the food records were acceptable. The main reasons for rejection of a returned food record were incomplete data or energy intake less than 3350 $\mathrm{kJ} /$ day. The response rate was $87 \%$ from persons who were instructed for food diaries and 66\% from the total subsample. ${ }^{9}$ Persons who did not participate with a three day food record but gave information of food frequencies were more often single and with lower education than participants of dietary survey. Non-participants of the dietary survey reported higher milk consumption on food frequency questionnaire than participants (data not shown).

\section{Simulation procedure}

Foodstuffs were selected for study on the basis of decisions already taken with regard to fortification and current applications for fortification. Also the frequency of the consumption of selected foods was taken into account as being an important factor when talking about food fortification. ${ }^{11}$ On the other hand the use of calcium supplements was not taken in to consideration in calculations. In Finland, calcium has been added so far to fruit juice and corresponding concentrates up to the level in milk on the basis of current national legislation (Decision of the Ministry of Trade and Industry on addition of vitamins and certain other substances to foodstuffs 113/1998) or individual licences relating to fortification of particular fruit drinks. However, in the calculations fruit juice, other juices and drinks were used. Skimmed dairy products fortified with calcium are also on the market with calcium contents 1.5 times higher than those of ordinary dairy products are. The industry and importers also wish to launch more foods that are fortified with calcium, for example, hot or
Table 2 Consumption of milk products in the lowest and highest decile of calcium intake in Finnish adults

\begin{tabular}{|c|c|c|}
\hline & \multicolumn{2}{|c|}{ Mean consumption (g/day) } \\
\hline & $\begin{array}{l}\text { Lowest decile of } \\
\text { calcium intake }\end{array}$ & $\begin{array}{l}\text { Highest decile of } \\
\text { calcium intake }\end{array}$ \\
\hline \multicolumn{3}{|c|}{ Milk and sour milk* } \\
\hline men & 47 & 924 \\
\hline women & 63 & 568 \\
\hline \multicolumn{3}{|l|}{ Cheese $\dagger$} \\
\hline men & 7 & 69 \\
\hline women & 11 & 64 \\
\hline \multicolumn{3}{|c|}{ Yoghurt and ice cream } \\
\hline men & 9 & 61 \\
\hline women & 8 & 64 \\
\hline \multicolumn{3}{|c|}{ Other milk products } \\
\hline men & 3 & 5 \\
\hline women & 4 & 5 \\
\hline \multicolumn{3}{|c|}{ All milk products } \\
\hline men & 66 & 1059 \\
\hline women & 86 & 701 \\
\hline
\end{tabular}

cold breakfast cereals, and wheat and mixed grain bread or bread flour. Foodstuffs studied and their calcium contents are shown in table 1.

Consumption of food and intakes of nutrients were calculated to obtain calcium intake deciles by sex, using SAS statistical software, on the basis of food consumption data from the 1992 FINDIET survey. Definition of calcium intake deciles allowed extremes of calcium intakes to be identified. The extent of the material meant that division into centiles would have resulted in excessively small group sizes. Consumption of foodstuffs by the population group representing the uppermost calcium intake decile is represented by the mean (table 2), and nutritional intake data are represented by both mean and the median (table 3).

In calculations it was assumed that the unfortified foodstuffs included were entirely replaced by fortified products. Mean consumption of foodstuffs in the uppermost calcium intake decile was used in calculations. Daily calcium intakes $(\mathrm{mg})$ from particular foodstuffs were calculated from a knowledge of amounts of calcium $(\mathrm{mg})$ per $100 \mathrm{~g}$ of each foodstuff and the amount of each product $(\mathrm{g})$ consumed per day. The extra calcium contributed by each fortified product was added to the basic dietary calcium intake of the uppermost decile (derived from nutritional intake data from the 1992 FINDIET survey) (table 4).

The highest possible intake of calcium was determined by adding to the calcium level of the diet of the uppermost decile the amount of calcium that would be contributed if all existing fortified foodstuffs and all products in respect of which a licence for fortification had been requested entirely replaced the corresponding unfortified foodstuffs. Similar calculations were also performed for the people in the lowest calcium intake decile. Results are shown in figures 1 and 2.

\section{RESULTS}

On average, Finnish adults received amounts of calcium from their diet well in excess of the minimum requirement and of the daily recommended adequate intake. The mean calcium intake for men was $1197 \mathrm{mg}$ per day, for women $996 \mathrm{mg}$ (table $3)$. Even those in the lowest calcium intake decile received amounts of calcium exceeding the minimum average requirement. Mean calcium intakes in the uppermost decile were $2315 \mathrm{mg} /$ day for men, $1812 \mathrm{mg} /$ day for women.

Seventy four per cent of the calcium in the diet came from milk and dairy products. ${ }^{9}$ Whether calcium intake is high or low therefore depends mainly on consumption of dairy products (table 2). On average, men in the uppermost calcium 
Table 3 Intake of calcium and energy in all subjects and in the lowest and highest decile of calcium intake

\begin{tabular}{|c|c|c|c|c|c|c|}
\hline & \multicolumn{2}{|c|}{ All subjects } & \multicolumn{2}{|c|}{$\begin{array}{l}\text { Lowest decile of } \\
\text { calcium intake }\end{array}$} & \multicolumn{2}{|c|}{$\begin{array}{l}\text { Highest decile of } \\
\text { calcium intake }\end{array}$} \\
\hline & Mean & Median & Mean & Median & Mean & Median \\
\hline \multicolumn{7}{|l|}{ Number } \\
\hline men & 870 & & 87 & & 87 & \\
\hline women & 991 & & 99 & & 99 & \\
\hline \multicolumn{7}{|c|}{ Energy intake ( $\mathrm{J} /$ day) } \\
\hline men & 10380 & 10109 & 7593 & 7370 & 14221 & 13249 \\
\hline women & 7808 & 7682 & 5979 & 5806 & 10463 & 10088 \\
\hline \multicolumn{7}{|c|}{ Calcium intake (mg/day) } \\
\hline men & 1197 & 1118 & $435^{*}$ & 454 & $2315 \ddagger$ & 2151 \\
\hline women & 996 & 947 & $439 \dagger$ & 472 & $1812 \S$ & 1715 \\
\hline \multicolumn{7}{|c|}{ Calcium intake (mg/M) } \\
\hline men & 116 & 114 & 61 & 57 & 170 & 162 \\
\hline women & 129 & 126 & 78 & 70 & 179 & 175 \\
\hline
\end{tabular}

intake decile consumed almost $1000 \mathrm{~g} /$ day of milk, sour milk and yoghurt, and ate about $70 \mathrm{~g} /$ day of cheese. The corresponding figures for women in the uppermost decile were almost $600 \mathrm{~g} /$ day and about $65 \mathrm{~g} /$ day. On average, people in the lowest calcium intake decile consumed only about 60 to $80 \mathrm{~g} /$ day of dairy products, of all kinds. The energy intake of people in the uppermost calcium intake decile was twice that of people in the lowest calcium intake decile (table 3).

\section{Results of simulation}

If unfortified juice had been replaced by products fortified with calcium the calcium intakes of the men in the uppermost calcium intake decile would have been on average about 158 mg per day higher (table 4). In men in the uppermost calcium intake decile, total calcium intake $(2473 \mathrm{mg} /$ day) would then have approached the tolerable upper intake level. Fortification of juice would have increased total calcium intake in the uppermost calcium intake decile of women to almost 2000 $\mathrm{mg} /$ day. In the lowest calcium intake decile, consumption of calcium fortified juice rather than unfortified juice would have increased daily calcium intakes to over $600 \mathrm{mg}$ for men, to about $550 \mathrm{mg}$ for women (results not shown).

If unfortified milk consumed had been entirely replaced by calcium fortified milk, calcium intake from milk alone would have increased in men in the uppermost calcium intake decile to about $1000 \mathrm{mg} /$ day. Calcium intake would then have exceeded the tolerable upper intake level by almost $200 \mathrm{mg}$ in men (table 4). In women calcium intake would have been about $2000 \mathrm{mg} /$ day. Replacement of unfortified milk by calcium fortified milk would not have made much difference in the lowest calcium intake decile because little milk is drunk by men and women in whom calcium intakes are very low.

If hot or cold breakfast cereals had been fortified with calcium in accordance with applications for fortification, and if all porridge or other hot or cold breakfast cereals had been replaced in men in the uppermost calcium intake decile by the corresponding calcium fortified products calcium intake would have risen to near the tolerable upper intake level (2416 $\mathrm{mg} /$ day) (table 4). In women under corresponding circumstances it would have remained below $2000 \mathrm{mg} /$ day. Calcium fortification of porridges or other hot or cold breakfast cereals would have not greatly altered calcium intake in the lowest calcium intake decile because people in whom calcium intake is low do not eat large amounts of porridge or cold breakfast cereals.

If wheat and mixed grain bread had been fortified with calcium to a level of $472 \mathrm{mg} / 100 \mathrm{~g}$ (table $\mathrm{l}$ ), calcium intakes of men in the uppermost calcium intake decile would have exceeded the tolerable upper intake level. Such fortification of bread would not have caused any problem in women (table 4). It would have had a beneficial effect in people whose calcium

Table 4 The impact of calcium fortification of four foods to calcium intake in the highest calcium intake decile in adult Finns

\begin{tabular}{|c|c|c|c|}
\hline & $\begin{array}{l}\text { Food use in the } \\
\text { highest calcium decile } \\
\mathrm{g} / \mathrm{d}^{*}\end{array}$ & $\begin{array}{l}\text { Calcium intake } \\
\text { increase } \mathrm{mg} / \mathrm{d} \text {, when } \\
\text { ordinary foods are } \\
\text { substituted with } \\
\text { fortified products }\end{array}$ & $\begin{array}{l}\text { Calcium intake in the } \\
\text { highest calcium decile } \\
\text { when ordinary foods } \\
\text { are substituted with } \\
\text { fortified products } \neq\end{array}$ \\
\hline \multicolumn{4}{|l|}{ Men $(n=87)$} \\
\hline Fruit juice and fruit drinks & 132 & 158 & 2473 \\
\hline Low fat and fat free milk & 620 & 372 & 2687 \\
\hline Hot and cold breakfast cereals & 117 & 101 & 2416 \\
\hline Wheat and mixed grain bread $\dagger$ & 71 & 335 & 2650 \\
\hline Total intake & & 966 & 3281 \\
\hline \multicolumn{4}{|l|}{ Women $(n=99)$} \\
\hline Fruit juice and fruit drinks & 146 & 175 & 1987 \\
\hline Low fat and fat free milk & 356 & 214 & 2026 \\
\hline Hot and cold breakfast cereals & 96 & 91 & 1903 \\
\hline Wheat and mixed grain bread $\dagger$ & 65 & 307 & 2119 \\
\hline Total intake & & 787 & 2599 \\
\hline
\end{tabular}

*FINDIET 1992 survey (Kleemola et al 1994); †no rye or crisp bread included; łbasic dietary calcium intake: men $2315 \mathrm{mg}$, women $1812 \mathrm{mg}$. 


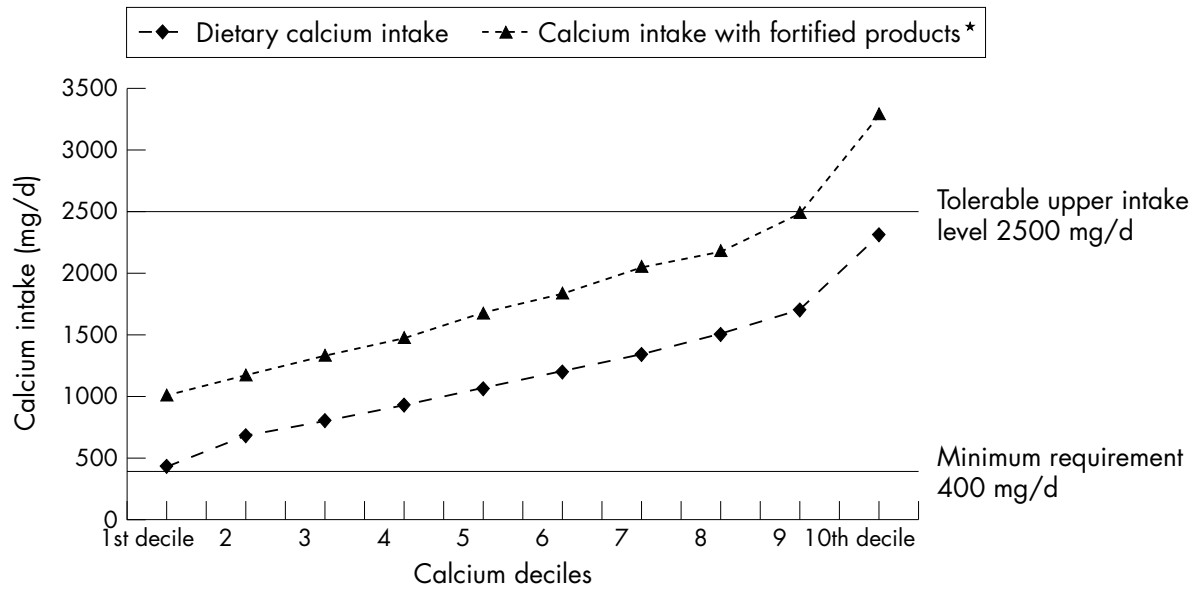

Figure 1 Intake of dietary calcium and additional maximum effect of fortified products to total calcium intake in adult Finnish men. ${ }^{*}$ Fortified fruit juice and fruit drinks, low fat and fat free milk, hot and cold breakfast cereals and wheat and mixed grain bread with $100 \%$ consumption.

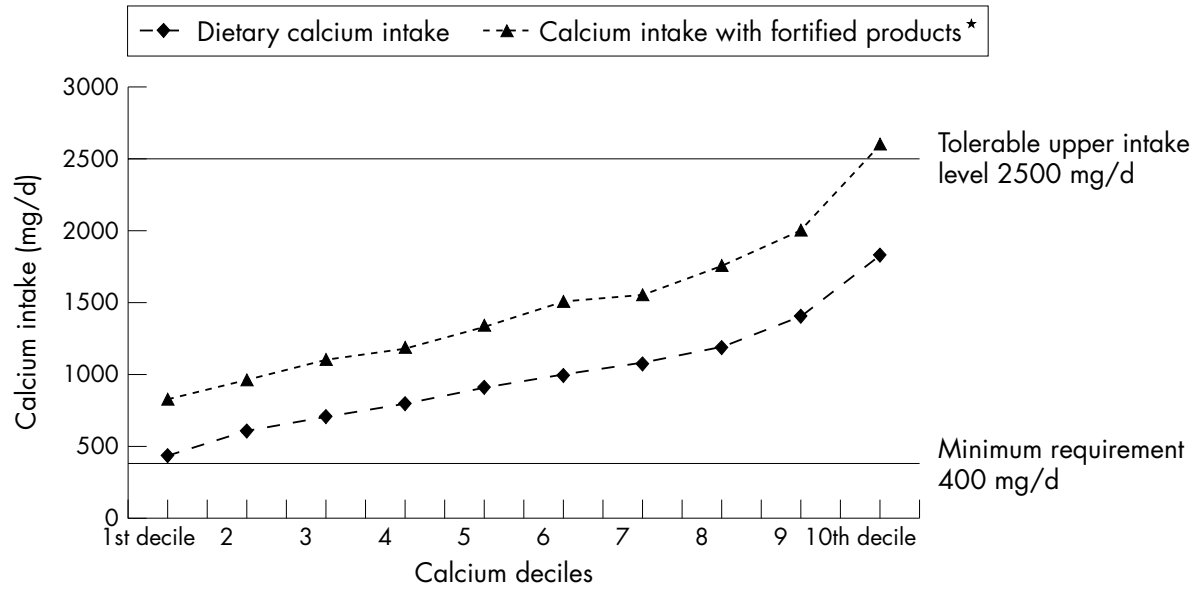

Figure 2 Intake of dietary calcium and additional maximum effect of fortified products to total calcium intake in adult Finnish women. *Fortified fruit juice and fruit drinks, low fat and fat free milk, hot and cold breakfast cereals and wheat and mixed grain bread with $100 \%$ consumption.

intakes were low. In the lowest decile of calcium intake women's daily intake of calcium would have risen to $650 \mathrm{mg}$ and men's intake to nearly $800 \mathrm{mg}$ per day.

The above mentioned estimates regarding calcium intakes relate to fortification of only one food group at a time (fruit juice and fruit drinks; semiskimmed or skimmed milk; hot or cold breakfast cereals; wheat and mixed grain bread) with calcium, in accordance with existing regulations or applications submitted by producers. If all of the groups of foodstuffs were replaced by corresponding calcium fortified foodstuffs cumulative calcium intake would rise in the uppermost calcium intake deciles to over $3000 \mathrm{mg} / \mathrm{day}$ for men, and would even exceed the tolerable upper intake level for women (table 4, figs 1 and 2).

\section{DISCUSSION}

The results of the study indicate that Finns on average receive enough calcium via their diet. Even those in the lowest calcium intake decile receive calcium exceeding the minimum requirement. Calcium intake in Finland depends greatly on consumption of dairy products: Finns receive about three quarters of their calcium from this source. The greater the energy content of the diet, the greater the extent to which need for calcium is met. In Finland, persons in the uppermost calcium intake decile receive from their diet over twice the recommended amount of calcium, although calcium intake does not exceed the tolerable upper intake level of 2500 mg/day. The used three days record was regarded to measure realiably the consumption of milk and calcium intake because almost $80 \%$ of Finnish adult population consumes milk daily. ${ }^{12}$ It is possible that proportions of consumers are lower during the weekend, but the weekend is also covered by three days food diaries. Even among underreporters the calcium intake was observed to be rather similar with the rest of the population. ${ }^{13}$ In Finland there is hardly any overestimation of milk consumption because milk consumption by FFQ was even higher among non-participants than among participants of the dietary survey.

A number of Finns do not consume dairy products because of lactose intolerance or milk allergy, or for other reasons. Prevalence of lactose intolerance in Finland is less than 20\% according to review article by Sahi. ${ }^{14}$ The food industry wishes to provide people with lactose intolerance with the opportunity of obtaining the calcium they need from low lactose and lactose free milk products as well as from different fortified products.

As wishes to engage in fortification have increased, the National Food Agency, the Finnish authority responsible for decisions relating to fortification has begun to estimate intakes of nutrients used in fortification, such as calcium, from normal diets, and the effects of fortification. Possible benefits of fortification and health risks are both taken into account. Examination of distributions of nutritional intakes and estimation of how fortification of various foodstuffs 


\section{Key points}

- The consumption of milk and milk products (excluding butter) is in Finland the highest (374 kg/year/person) in the whole Europe.

- On average, Finnish adults receive enough calcium from their diet. In Finland three quarters of the dietary calcium comes from milk and dairy products.

- Men in the uppermost calcium intake decile have more than twice the calcium intake compared with the recommended daily intake.

- Finnish men in the uppermost calcium intake decile may have a harmful calcium intake due to adding calcium to foods.

- Choosing the carrier foodstuffs for calcium so that fortification would be accurately targeted is problematic in Finland.

would alter nutritional intakes at extremes of distributions are needed. For calculations to be based on diets and nutritional intake sufficiently detailed and extensive food consumption data and up to date nutritional data relating to foodstuffs are required.

The estimates of calcium intakes in this study were based on consumption and possible fortification of four groups of foodstuffs. Data relating to juice, hot or cold breakfast cereals, milk products, and breads, either fortified now or for which applications to fortify in Finland have been made, were used. In addition to these products, several calcium fortified products are marketed in EU countries and may be imported to Finland. The greater the extent to which calcium fortification of foodstuffs is undertaken, the greater the risk, obviously, that some people will get amounts of calcium exceeding the tolerable upper intake level.

The primary object of this study was to define the worst case scenario that could arise in practice. Accordingly only calcium fortified products already on the market and those in relation to which applications for fortification have been submitted were included in the calculations. Market shares of calcium fortified products were not taken into account because there are several calcium fortified products, which are only seeking entry into the Finnish market. In attempting to assess the effects of calcium fortification, it was assumed that the unfortified product was always completely replaced by the fortified equivalent, on the basis that some group of consumers might act in this way. As authorities making decisions have responsibility for the safety of foodstuffs, we felt that use of a maximum intake model to be important, as doing so reflects the need for precautionally principle, which should be respected according the FAO/WHO Codex Alimentarius in such decision making.This approach is supported by research findings ${ }^{15-17}$ showing that dietary supplements are often used by people whose basic diets and nutritional intakes are in themselves in accordance with recommendations.

There was no specific evidence on the bioavailibility of calcium salts added to foods. It was however assumed that calcium was well metabolised because the compounds used are accepted by EU different directives. The responsibility of approving bioavailability of added nutrients in different foods is one of the important issues that should be discussed while giving the legislation on food fortification.

A regular calcium intake of over $2500 \mathrm{mg} /$ day has been found to be harmful, especially if intake of vitamin D is also high. ${ }^{2}$ An excessive intake of calcium can result in hypercalcaemia and calciuria. ${ }^{18}$ High calcium levels in the urine can result in renal damage ${ }^{19}$ and development of kidney stones. ${ }^{16}$ There is increasing evidence from research of a connection between high calcium intakes and prostate cancer. ${ }^{2021}$ Excessive intake of calcium can also impair absorption of iron, ${ }^{22}$ magnesium, phosphorus and zinc. ${ }^{1623}$

Fortification of milk and bread with calcium to levels currently approved, or to levels in relation to which applications for fortification have been made, could increase the calcium intake of men aged 25 to 64 in the highest decile to levels with potentially untoward health effects. On average there are over 100000 such people in Finland. In contrast, fortification of juice or of hot or cold cereals with calcium would not increase calcium intakes excessively. However, there is a national general licence to fortify juice and corresponding concentrates with calcium. Such fortification could result in calcium intakes of men in the uppermost calcium intake decile rising to such an extent that any additional fortification could result in problems. The tolerable upper intake level of calcium for women would be exceeded if all unfortified foodstuffs considered in the study were replaced with corresponding products fortified with calcium. The results of the study calculations clearly indicate that risk of excessive calcium intake would increase in persons whose diets have high energy contents if unfortified foodstuffs were replaced with fortified products.

Fortification of dairy products or of hot or cold breakfast cereals with calcium would not improve the situation of people with low calcium intake because, without dietary changes, such people do not consume enough of these products for fortification to have much effect. In contrast, fortification of juices and bread with calcium would considerably increase calcium intakes in this group.

As the fortification of bread with calcium could result in excessive intake of calcium by men in the uppermost calcium intake decile, it cannot be recommended. In addition, the Finnish Nutrition Recommendations ${ }^{3}$ encourage consumption of large quantities of wholemeal products such as bread. It would be undesirable in relation to public health if consumption of bread had to be limited because it had been fortified with calcium.

Of the foodstuffs studied, juice would seem to be the best targets for calcium fortification because the consumption of calcium fortified juice would increase intakes of calcium by people whose consumption of dairy products is low but would not result in creation of a health risk to men in the uppermost calcium intake decile.

The results of the study show that liberal fortification could result in health risks in relation to some population groups. Fortification of foodstuffs can be valuable in improving the nutritional situations of people whose nutritional intakes are low. In this case, the diets of the population groups studied need to be determined and there is a need to ensure that no group of consumers could get too much, even toxic amounts, of the nutrient used in fortification. Decision making authorities need internationally approved limits relating to nutrient requirements and tolerable upper intake levels in order to be able to apply the precautionally principle. To optimise decision making and allow nutritional intakes to be monitored adequately high quality data relating to food consumption and nutrition in respect of different population groups need to be available, together with information relating to fortified foodstuffs already marketed and to products that are only seeking entry into the Finnish market. Other means of implementing nutritional policy, such as consumer education, provision of information, and provision of dietary supplements to particular population groups, need to be used, together with selective fortification, to improve nutritional intakes.

\section{ACKNOWLEDGEMENTS}

\section{Authors' affiliations}

A Suojanen, S Raulio, National Food Agency, Finland

M-L Ovaskainen, National Public Health Institute, Nutrition Unit, Finland

\section{REFERENCES}

1 Nordic Council of Ministers. Addition of nutrients to food-principles and practices. Copenhagen: TemaNord, 1995:643. 
2 Nordic Council of Ministers (Nordiska Ministerrådet) Nordiska näringsrekommedationer. Copenhagen: Nord, 1996:28.

3 National Nutrition Council. Finnish nutrition recommendations. Committee Report 1998. Helsinki: 1999.

4 Commission of the European Communities. Nutrient and energy intakes for the European Community. Reports of the Scientific Committee for Food. Opinion expressed on 11 December 1992. Directorate-General Industry, 1993:150-7.

5 Food and Nutrition Board, Institute of Medicine, National Academy of Sciences. Dietary reference intakes for calcium, phosphorus, magnesium vitamin D, and fluoride. Standing Committee on the Scientific Evaluation of Dietary Reference Intakes. Washington DC: National Academy Press, 1997:71-145.

6 FAOSTAT. Statistical Databases. Nutrition data. Food balance sheets. http://apps.fao.org/page/collections? subset=nutrition, 2001.

7 Delmas PD, Fraser M. Strong bones in later life: luxury or necessity? Bull World Health Organ 1999;77:416-22.

8 Aromaa A, Koskinen S, Huttunen J, eds. Health in Finland. Helsinki: National Public Health Institute (KTL), Ministry of Social Affairs and Health, 1999.

9 Kleemola P, Virtanen M, Pietinen P. The 1992 Dietary Survey of Finnish Adults. Helsinki : Publications of the National Public Health Institute B2/1994, 1994

10 Roos E, Prättälä R, Lahelma $E$, et al. Modern and healthy? Socioeconomic differences in the quality of diet. Eur J Clin Nutr 1996;50:753-60.

11 Melse-Boonstra A, de Pee S, Martini E, et al. The potential of various foods to serve as a carrier for micronutrient fortification, data from remote areas in Indonesia. Eur J Clin Nutr 2000;54:822-7.
12 National Public Health Institute. The National FINDIET 1997 Study. Helsinki: Publications of the National Public Health Institute B 8/1998, 1998.

13 Hirvonen T, Männistö S, Roos E, et al. Increasing prevalence of underreporting does not necessarily distort dietary surveys. Eur J Clin Nutr 1997:51:297-301.

14 Sahi T. Genetics and epidemiology of adult-type hypolactasia. Scand J Gastroenterol 1994;29 (suppl 202):7-20.

15 Kaartinen P, Ovaskainen ML, Pietinen P. The use of dietary supplements among Finnish adults. Scand J Nutr 1997;41:13-17.

16 Whiting SJ, Wood RJ. Adverse effects of high-calcium diets in humans. Nutr Rev 1997:55: 1-9.

17 Kirk SFL, Cade JE, Barrett JH, et al. Diet and lifestyle characteristics associated with dietary supplement use in women. Public Health Nutrition 1999;21:69-73.

18 Avioli LV. Calcium and phosphorus. In: Shils ME, Young VR, eds. Modern nutrition in health and disease. 7th edn. Philadelphia: Lea and Febiger, 1988: 142-58.

19 Weaver CM, Heaney RP. Calcium. In: Shils ME, Olson JA, Shike M, et al, eds. Modern nutrition in health and disease. Baltimore: Williams and Wilkins, 1999.

20 Chan JM, Giovannucci E, Andersson S-O et al. Dairy products, calcium phosphorous, vitamin $D$, and risk of prostate cancer (Sweden). Cancer Causes Control 1998;9:559-66.

21 Giovannucci E, Rimm EB, Wolk A, et al. Calcium and fructose intake in relation to risk of prostate cancer. Cancer Res 1998;58:442-7.

22 Cook JD, Dassenko SA, Whittaker P. Calcium supplementation: effect on iron absorption. Am J Clin Nutr 1991;53:106-11.

23 Wood RJ, Zheng JJ. High dietary calcium intakes reduce zinc absorption and balance in humans. Am J Clin Nutr 1997;65:1803-9.

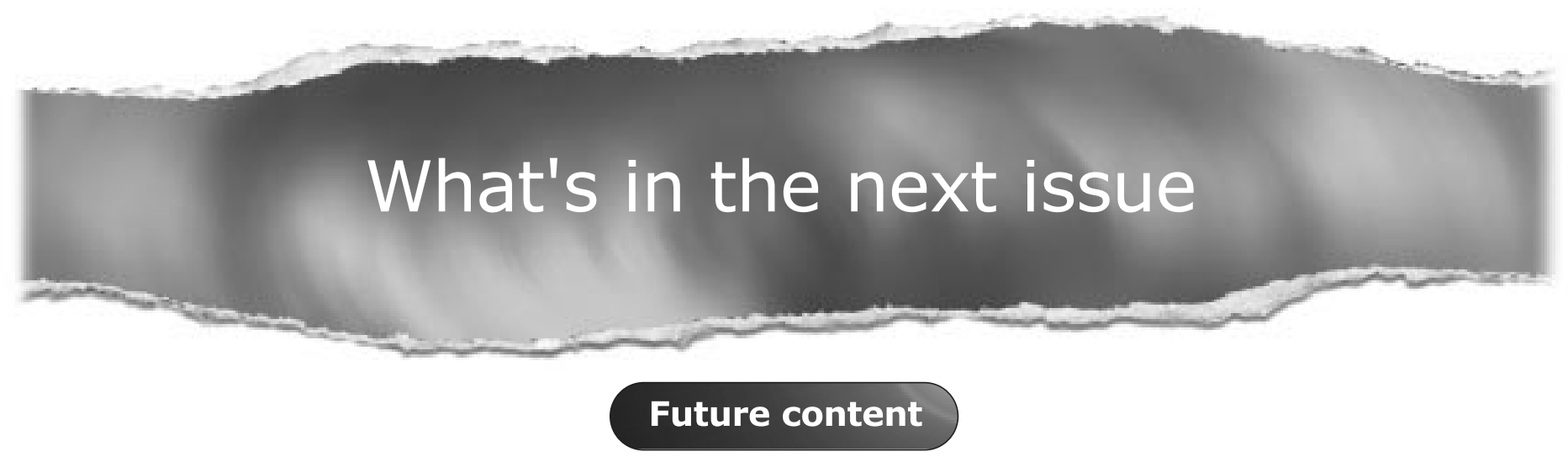

See which articles have just been accepted for publication and preview the table of contents for the next issue a month before it is published

www.jech.com 